\title{
Determination of Chromium(VI) in Electronics Materials Using Trioctylamine Modified Carbon Paste Electrode
}

\author{
Juan XU, ${ }^{* * *}$ Yong Kong, ${ }^{*}$ Wenchang WANG, ${ }^{*}$ Zhidong CHEN, ${ }^{* \dagger}$ and Shiping YAO*** \\ *Jiangsu Polytechnic University, Qualtec Co. Ltd., Changzhou 213164, P. R. China \\ **Jiangsu Fine Petroleum Chemical Key Laboratories, Changzhou 213164, P. R. China \\ ***ChemChina Petroleum Development Corporation, Beijing 100080, P. R. China
}

\begin{abstract}
A trioctylamine (TOA) modified carbon paste electrode (TOA/CPE) was firstly utilized to determine $\mathrm{Cr}(\mathrm{VI})$ in electronics materials. The effects of preconcentration conditions, that is, TOA amount and accumulation time on $\mathrm{Cr}(\mathrm{VI})$ accumulation were examined and the optimum experiment conditions for the determination were identified. A sensitive reduction peak in the stripping voltammogram at $-0.45 \mathrm{~V}$, a characteristic of trace $\mathrm{Cr}(\mathrm{VI})$, was detected when the accumulation time was $10 \mathrm{~min}$. Under optimized conditions, TOA/CPE demonstrated an enhanced sensitivity for $\mathrm{Cr}(\mathrm{VI})$, providing a low detection limit $(S / N=3)$ at $3.4 \times 10^{-9} \mathrm{M}$. Interference studies also displayed high selectivity of the TOA/CPE for $\mathrm{Cr}(\mathrm{VI})$; this electrode can accurately determine $\mathrm{Cr}(\mathrm{VI})$ in the presence of $\mathrm{Cr}(\mathrm{III})$ (600-fold concentration) and other interfering cations.
\end{abstract}

(Received July 31, 2009; Accepted August 31, 2009; Published December 10, 2009)

\section{Introduction}

$\mathrm{Cr}(\mathrm{VI})$ was proved to be detrimental to mucous membranes and kidney, and has been classified as a second inorganic contaminant in the environment, although $\mathrm{Cr}(\mathrm{III})$ is considered to be biologically essential in mammals for the maintenance of glucose, lipid, and protein metabolism..$^{1,2}$

Recently, great amounts of $\mathrm{Cr}(\mathrm{VI})$ in the form of $\mathrm{Cr}_{2} \mathrm{O}_{7}{ }^{2-}$ have been entering into environment via discarded electronics materials, and have led to high toxicity and carcinogenicity to humans as the electronics industry has rapidly grown. On the other hand, $\mathrm{Cr}$ (III) and $\mathrm{Cr}$ (VI) usually coexists in the electronics materials, which results in a huge inconvenience in the accurate determination of $\mathrm{Cr}(\mathrm{VI})$. No effort has been made to develop highly sensitive and selective electrodes for the determination of $\mathrm{Cr}(\mathrm{VI})$ in electronics materials.

Many sophisticated analytical techniques, such as UV-visible spectrophotometry, ${ }^{3}$ diffuse reflectance Fourier-transform infrared spectroscopy, ${ }^{4}$ atomic adsorption spectrophotometry, ${ }^{5}$ inductively coupled plasma-atomic emission spectrometry, ${ }^{6}$ and electrochemical methods ${ }^{7-10}$ have been employed for the determination of trace levels of $\mathrm{Cr}(\mathrm{VI})$ in natural water. Among them, the determination of $\mathrm{Cr}(\mathrm{VI})$ with the aid of a carbon paste electrode (CPE) and some chemical modifier has been proved to be the most promising alternatives because of their high sensitivity, low detection limit, relative simplicity, low cost of materials, and ability to distinguish $\mathrm{Cr}$ (VI) from $\mathrm{Cr}(\mathrm{III}) .^{11,12}$

The effective preconcentation of $\mathrm{Cr}(\mathrm{VI})$ from $\mathrm{Cr}(\mathrm{VI})$ and $\mathrm{Cr}(\mathrm{III})$ mixture and prevention of the interference of $\mathrm{Cr}$ (III) to $\mathrm{Cr}(\mathrm{VI})$ are both essential to obtain the best results in determination of $\mathrm{Cr}(\mathrm{VI})$. As reported recently, trioctylamine

† To whom correspondence should be addressed.

E-mail: cjytion@163.com; czd_chen@yahoo.com
(TOA) has a strong affinity for $\mathrm{Cr}(\mathrm{VI})$, and can effectively extract and concentrate $\mathrm{Cr}(\mathrm{VI})$ through a highly selective anion-exchange reaction. ${ }^{13}$ In the present work, TOA was firstly utilized to modify carbon paste electrodes (TOA/CPE) for determination of $\mathrm{Cr}(\mathrm{VI})$ in electronics materials.

\section{Experimental}

Reagents and chemicals

Trioctylamine (TOA), chloroform, spectroscopic graphite powder, liquid paraffin, potassium dichromate, chromium chloride, copper chloride, iron chloride, potassium chloride, ammonium chloride, sodium chloride, palladium chloride, and cadmium chloride were obtained from the Sinopharm Chemical Reagent Co. (China) and used as received. All other chemicals, unless mentioned otherwise, used in this investigation were of analytical grade (99\%). All of the solutions were prepared with Milli-Q (Millipore) A-10 gradient deionized water. Freshly prepared solutions were used in all experiments.

A $\mathrm{Cr}(\mathrm{VI})$ stock solution $(0.01 \mathrm{M})$ was prepared by dissolving $2.9418 \mathrm{~g}$ potassium dichromate $\left(\mathrm{K}_{2} \mathrm{Cr}_{2} \mathrm{O}_{7}\right)$ in a $1-\mathrm{L} 0.15 \mathrm{M}$ $\mathrm{H}_{2} \mathrm{SO}_{4}$ solution. Model solution of $\mathrm{Cr}(\mathrm{VI})$ was obtained by diluting a stock solution of $\mathrm{Cr}(\mathrm{VI})$ with a $0.15 \mathrm{M} \mathrm{H}_{2} \mathrm{SO}_{4}$ solution. Working solution of other metals was prepared from their own salts above mentioned with a $0.15 \mathrm{M} \mathrm{H}_{2} \mathrm{SO}_{4}$ solution.

\section{Apparatus}

Electrochemical measurements were performed using TOA/CPE as a working electrode, $\mathrm{Pt}$ wire as an auxiliary electrode and a saturated calomel electrode (SCE) as a reference electrode. The $\mathrm{Cr}(\mathrm{VI})$ concentration was determined by making a stripping voltammogram at a computer-controlled CHI660 electrochemical analyzer in the range of -1.0 to $0.6 \mathrm{~V}$ with different scan rates. Dissolved oxygen was removed by purging 
nitrogen, and the experimental temperature was kept at $25 \pm 1^{\circ} \mathrm{C}$ For $\mathrm{pH}$ measurements, a Metrohm $691 \mathrm{pH}$ meter was used. The UV-vis absorption spectra of $\mathrm{Cr}(\mathrm{VI})$ were determined using a 1240 UV-visible spectrophotometer (Japan).

\section{Procedure}

Preparation of TOA/CPE. Different amounts of TOA $(0.05-0.20 \mathrm{~g})$ were sufficiently commixed with $1.9 \mathrm{~g}$ chloroform, followed by the addition of $0.667 \mathrm{~g}$ spectroscopic graphite powder and complete blend. After evaporating the chloroform, $0.20 \mathrm{ml}$ liquid paraffin $(0.1668 \mathrm{~g})$ was added and TOA modified carbon paste was prepared by intimately homogenizing. The ready-made paste with an ohmic resistance of about $5 \Omega$ was then packed into a piston-driven carbon-paste holder. The electrode surface was renewed by the extrusion of approximately $0.5 \mathrm{~mm}$ carbon paste from the holder and smoothing with a filter paper. Typically, such a mechanical renewal of a carbon-paste surface is done when starting a new series of measurements (e.g. prior to the analysis of each sample).

Analysis of model solution. After preparing a $\mathrm{Cr}(\mathrm{VI})$ model solution to be analyzed and purging with $\mathrm{N}_{2}$ for $c a$. $5 \mathrm{~min}$, measurements were carried out in the cathodic stripping voltammetric mode. A typical experiment consisted of three consecutive steps with the following experimental conditions: a preconcentration step for $1-20$ min under a stirring condition, a washing step three times, and a stripping step run from +0.6 to $-1.0 \mathrm{~V}$ by applying different scan rates. For a comparison, nude $\mathrm{CPE}$ was directly inserted in the $\mathrm{Cr}(\mathrm{VI})$ model solution under the same condition. A mixture solution composed of $0.15 \mathrm{M}$ $\mathrm{K}_{2} \mathrm{SO}_{4}$ and $0.15 \mathrm{M} \mathrm{H}_{2} \mathrm{SO}_{4}$ was used as electrolyte.

Analysis of real sample. Electronic material scraps were pretreated using a wet nitration method. ${ }^{14-16}$ Then $0.5 \mathrm{~g}$ electronic material scraps were dissolved into a mixture solution of $2 \mathrm{~mL} \mathrm{HCl}$ and $\mathrm{HNO}_{3}(15 \mathrm{wt} \%)$. Fe and $\mathrm{Cu}$ elements were completely precipitated by adjusting the $\mathrm{pH}$ value to 9.5 and 11 , respectively. After boiling for $2-3 \mathrm{~min}$ and then cooling to room temperature, the above-mentioned solution was filtered, diluted to $10 \mathrm{~mL}$ using deionized water and used as a real sample solution. The analysis procedure for a real sample solution was in accordance with that for a model solution.

$\mathrm{The} \mathrm{Cr}(\mathrm{VI})$ concentration in a real sample was also determined by UV-visible spectrophotometry. The sample pretreatment process was identical to that by stripping voltammetry. According to literature reports, ${ }^{17}$ the detection wavelength was set at $372 \mathrm{~nm}$.

\section{Results and Discussion}

\section{Principles of the preconcentration process}

In acid surroundings, TOA can preconcentrate $\mathrm{Cr}(\mathrm{VI})$ in the form of $\mathrm{Cr}_{2} \mathrm{O}_{7}{ }^{2-}$ through an anion-exchange course. ${ }^{18,19}$ Firstly, TOA (represented as $\mathrm{R}_{3} \mathrm{~N}$ ) can be protonated according to Eq. (1):

$$
\mathrm{R}_{3} \mathrm{~N}+\mathrm{H}_{2} \mathrm{SO}_{4}=\mathrm{R}_{3} \mathrm{NH}^{+}+\mathrm{HSO}_{4}^{-} .
$$

Then $\mathrm{Cr}_{2} \mathrm{O}_{7}{ }^{2-}$ can be preconcentrated by $\mathrm{R}_{3} \mathrm{NH}^{+}$by the anion-exchange procedure according to Eq. (2):

$$
\mathrm{R}_{3} \mathrm{NH}^{+}+\mathrm{Cr}_{2} \mathrm{O}_{7}^{2-}=\left(\mathrm{R}_{3} \mathrm{~N}\right)_{2} \mathrm{C}_{\mathrm{r}} \mathrm{O}_{7} \text {. }
$$

Determination of $C r(V I)$ in model solution and real sample using TOA/CPE

Figure 1 presents stripping voltammograms of TOA/CPE and

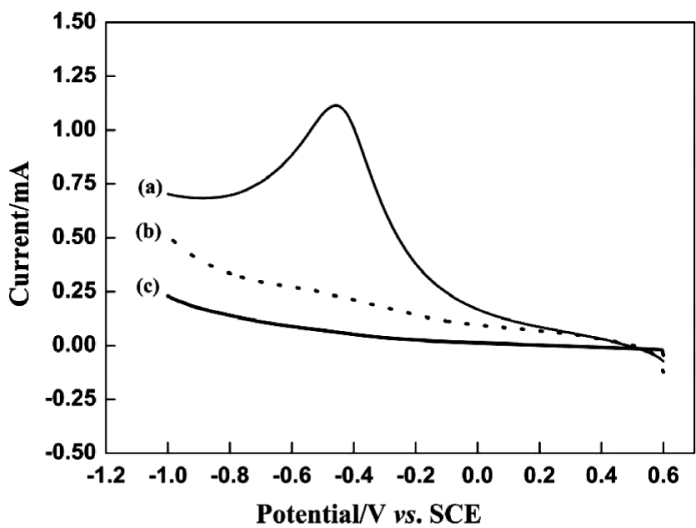

Fig. 1 Comparison of the reduction response for $\mathrm{Cr}(\mathrm{VI})$ at TOA/CPE $(\mathrm{a}, \mathrm{c})$ and nude CPE (b) before (c) and after ( $\mathrm{a}, \mathrm{b})$ the preconcentration process. Electrolyte, $0.15 \mathrm{M} \mathrm{K}_{2} \mathrm{SO}_{4}-\mathrm{H}_{2} \mathrm{SO}_{4}$; scan rate, $20 \mathrm{mV} / \mathrm{s}$; $\mathrm{Cr}(\mathrm{VI}), 1.0 \times 10^{-7} \mathrm{M}$.

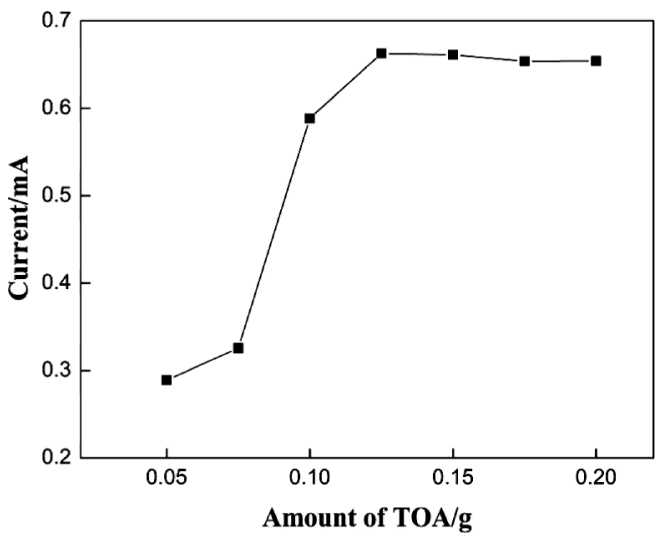

Fig. 2 Effect of the TOA amount on the reduction peak current of $\mathrm{Cr}(\mathrm{VI})$. $\mathrm{Cr}(\mathrm{VI}), 1.0 \times 10^{-7} \mathrm{M}$.

nude CPE before and after they were placed in a $\mathrm{Cr}(\mathrm{VI})$ model solution for $10 \mathrm{~min}$. The accumulation of $\mathrm{Cr}(\mathrm{VI})$ and its subsequent reduction at the TOA/CPE gave rise to an apparent reduction peak at $-0.45 \mathrm{~V}$ (curve a) compared to that obtained with nude CPE under otherwise identical conditions (curve b). Yet no reduction peak appeared before the TOA/CPE was treated with the preconcentration procedure (curve c). Similar results were obtained after TOA/CPE and nude CPE were placed in a real sample solution (curves not shown here). These above results proved that $\mathrm{Cr}(\mathrm{VI})$ could be effectively preconcentrated by TOA, which highly increased the electrochemical response of TOA/CPE to $\mathrm{Cr}(\mathrm{VI})$. On the other hand, the cathodic current for the TOA-free CPE is much larger than that for TOA/CPE before the preconcentration process, indicating that TOA helps to decrease the background current of CPE.

Influences of different operational parameters

Effect of the TOA amount on Cr(VI) accumulation. The role of TOA in our work was to preconcentrate $\mathrm{Cr}(\mathrm{VI})$ from the model or real solution, its amount greatly influenced the accumulated amount of $\mathrm{Cr}(\mathrm{VI})$, which shows that a condign amount of $\mathrm{Cr}(\mathrm{VI})$ is needed in the course of electrode preparation. Figure 2 shows the relationship of the reduction peak current with the amount of TOA when the weight ratio of graphite and paraffin is set at $1: 0.25 .{ }^{20}$ With an increase in the TOA amount, the peak current 


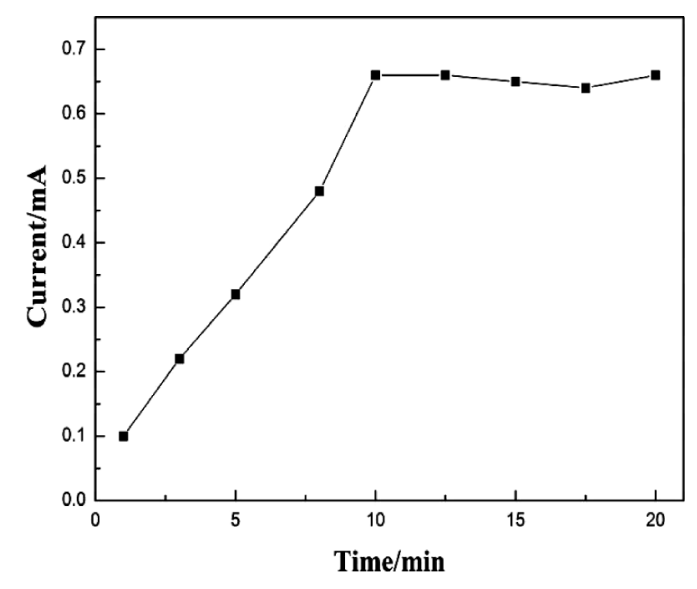

Fig. 3 Effect of the accumulation time on the reduction peak current of $\mathrm{Cr}(\mathrm{VI}) . \mathrm{Cr}(\mathrm{VI}), 1.0 \times 10^{-7} \mathrm{M}$.

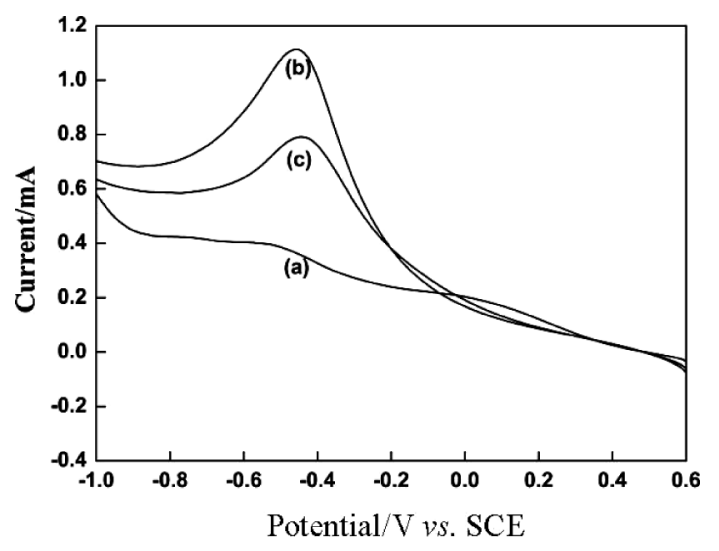

Fig. 4 Stripping voltammograms of $\mathrm{Cr}(\mathrm{VI})$ at TOA/CPE in $0.15 \mathrm{M}$ $\mathrm{HNO}_{3}-\mathrm{KNO}_{3}$ (a), $\mathrm{H}_{2} \mathrm{SO}_{4}-\mathrm{K}_{2} \mathrm{SO}_{4}$ (b) and $\mathrm{HCl}-\mathrm{KCl}$ (c) solutions, respectively.

goes up initially, culminates when the TOA amount is $0.125 \mathrm{~g}$ and remains stable even if the TOA amount increases afterwards, which means that the optimal weight ratio of the grafite/paraffin/TOA is $c a$. 1:0.25:0.19.

Influence of time on $\mathrm{Cr}(\mathrm{VI})$ accumulation. Figure 3 presents the reduction peak current value after TOA/CPE was placed in the model solution for different time. The reduction peak currents increased along with the accumulation time from 3 to $10 \mathrm{~min}$, and remained invariable up to $30 \mathrm{~min}$, which illuminates that $10 \mathrm{~min}$ is adequate for $\mathrm{Cr}(\mathrm{VI})$ accumulation. The reason why the cathodic response for $\mathrm{Cr}(\mathrm{VI})$ reaches a plateau is that all the TOA molecules are combined with $\mathrm{Cr}(\mathrm{VI})$ and the amount of the accumulated $\mathrm{Cr}(\mathrm{IV})$ culminates when the TOA/CPE is placed in a $\mathrm{Cr}(\mathrm{VI})$ solution for $10 \mathrm{~min}$.

Influence of electrolyte on Cr(VI) determination. Figure 4 illustrates stripping voltammograms of TOA/CPE in a $0.15 \mathrm{M}$ $\mathrm{H}_{2} \mathrm{SO}_{4}-\mathrm{K}_{2} \mathrm{SO}_{4}$, a $\mathrm{HCl}-\mathrm{KCl}$ and a $\mathrm{HNO}_{3}-\mathrm{KNO}_{3}$ solution, respectively. No reduction peak exists when $\mathrm{Cr}(\mathrm{VI})$ is determined in $\mathrm{HNO}_{3}-\mathrm{KNO}_{3}$ solution (curve a), while obvious reduction peak appears when $\mathrm{Cr}(\mathrm{VI})$ is determined in $\mathrm{H}_{2} \mathrm{SO}_{4}-\mathrm{K}_{2} \mathrm{SO}_{4}$ or $\mathrm{HCl}-\mathrm{KCl}$ solution. Moreover, the reduction peak current in $\mathrm{H}_{2} \mathrm{SO}_{4}-\mathrm{K}_{2} \mathrm{SO}_{4}$ solution (curve b) is higher than that in $\mathrm{HCl}-\mathrm{KCl}$ solution (curve c), indicating that the electrochemical response of $\mathrm{Cr}(\mathrm{VI})$ obtained in the $\mathrm{SO}_{4}{ }^{2-}$ system was better than that obtained in the $\mathrm{Cl}^{-}$system.

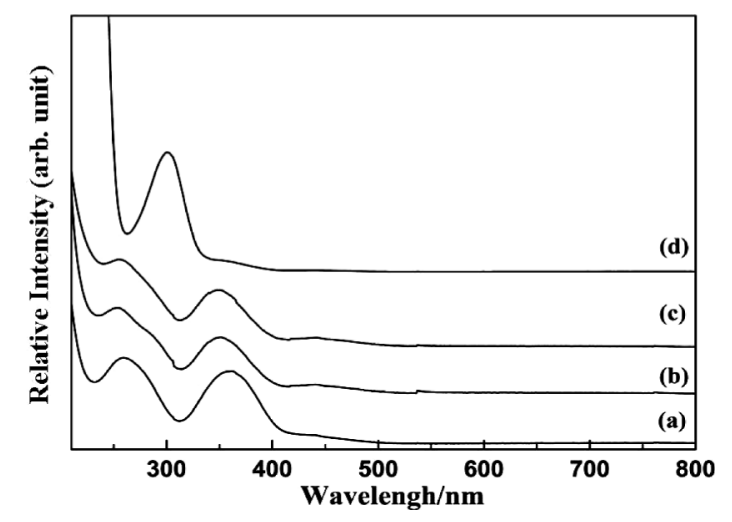

Fig. 5 Absorption spectra of a $0.01 \mathrm{mM} \mathrm{Cr}(\mathrm{VI})$ solution before (a) and after adding $0.30 \mathrm{mM} \mathrm{KCl}(\mathrm{b}), \mathrm{K}_{2} \mathrm{SO}_{4}(\mathrm{c})$ and $\mathrm{KNO}_{3}(\mathrm{~d})$.

Table 1 Interferences of various cations on the determination of $1.5 \times 10^{-5} \mathrm{M} \mathrm{Cr}(\mathrm{VI})$

\begin{tabular}{lc}
\hline \multicolumn{1}{c}{ Cation } & Acceptable maximum concentration/mM \\
\hline $\mathrm{K}^{+}, \mathrm{Na}^{+}, \mathrm{NH}_{4}^{+}$ & 10 \\
$\mathrm{Cr}^{3+}$ & 9 \\
$\mathrm{Fe}^{3+}$ & 3 \\
$\mathrm{Cu}^{2+}, \mathrm{Pd}^{2+}, \mathrm{Cd}^{2+}$ & 2 \\
\hline
\end{tabular}

To illuminate the effect of different anions on $\mathrm{Cr}(\mathrm{VI})$ determination, UV-visible spectra of the $\mathrm{Cr}(\mathrm{VI})$ solution were measured after $0.30 \mathrm{M} \mathrm{KCl}, \mathrm{K}_{2} \mathrm{SO}_{4}$ or $\mathrm{KNO}_{3}$ were added, as depicted in Fig. 5. $\mathrm{Cl}^{-}$and $\mathrm{SO}_{4}{ }^{2-}$ had no influence on the absorption curves of $\mathrm{Cr}(\mathrm{VI})$, while the absorption peak position changed after $\mathrm{NO}_{3}{ }^{-}$was added, which may be due to that $\mathrm{NO}_{3}{ }^{-}$ can fleetly complex with $\mathrm{Cr}(\mathrm{VI})$. Based on these results, a $\mathrm{H}_{2} \mathrm{SO}_{4}-\mathrm{K}_{2} \mathrm{SO}_{4}$ solution was chosen as an electrolyte to determinate $\mathrm{Cr}(\mathrm{VI})$ in our work.

Effect of the scan rate on the Cr(VI) determination. The change in the electrochemical reduction current with the scan rate was investigated, and it was found that the reduction peak current linearly increased with the scan rate; the linear equation is $i_{\mathrm{p}}=6.1218 \mathrm{v}+0.1471 \mathrm{in}$ the range of $20-200 \mathrm{mV} / \mathrm{s}$, indicating that this electrochemical course is mainly controlled by an adsorption process. ${ }^{21}$

\section{Maximum acceptable concentration of interfering cations}

The interfering effect of some cations on the analysis of $1.5 \times 10^{-5} \mathrm{M} \mathrm{Cr}(\mathrm{VI})$ was studied. Table 1 presents the maximum acceptable concentration of various interfering cations when the test error of $\mathrm{Cr}(\mathrm{VI})$ was set at $5 \%$. The determinations of $\mathrm{Cr}(\mathrm{VI})$ could be carried out in the presence of 600 -fold excess of $\mathrm{Cr}(\mathrm{III})$, and the presence of high concentrations of $\mathrm{K}^{+}, \mathrm{Na}^{+}$, $\mathrm{NH}_{4}^{+}, \mathrm{Fe}_{3}{ }^{+}, \mathrm{Cu}^{2+}, \mathrm{Pd}^{2+}$ and $\mathrm{Cd}^{2+}$ did not have any significant effect on the $\mathrm{Cr}(\mathrm{VI})$ signal. In a comparison with other reported methods, ${ }^{22}$ the interference effect of $\mathrm{Cr}$ (III) was greatly lowered.

\section{Calibration curve of $\mathrm{Cr}(\mathrm{IV})$ under the optimum conditions}

Figure 6 shows a calibration curve of $\mathrm{Cr}(\mathrm{VI})$ at the TOA/CPE after being treated with the above-mentioned optimum preconcentration procedure. The response current of $\mathrm{Cr}(\mathrm{VI})$ in the model solution showed a linear relationship with the concentration of $\mathrm{Cr}(\mathrm{VI})$ over the range of $5.0 \times 10^{-7}-1.0 \times$ $10^{-3} \mathrm{M}$. The equation and the correlation coefficient $(r)$ were $I=0.0292 C+0.7138(I, \mathrm{~mA} ; C, \mu \mathrm{M})$ and 0.9898 , respectively. Based on the above equation and the determined reduction 


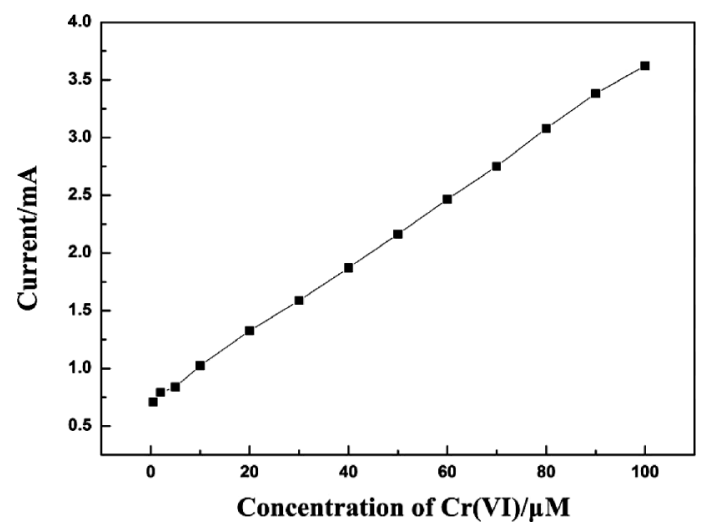

Fig. 6 Calibration curve of $\mathrm{Cr}(\mathrm{VI})$ at the TOA/CPE after being treated with the preconcentration procedure. Experimental conditions: TOA amount, $0.125 \mathrm{~g}$; accumulation time, $10 \mathrm{~min}$.

Table 2 Comparison of the concentration of $\mathrm{Cr}(\mathrm{VI})$ in electronic equipment scraps determined by stripping voltammetry or spectrophotometry

\begin{tabular}{ccc}
\hline \multirow{2}{*}{ Sample } & \multicolumn{2}{c}{ Concentration of Cr(VI) in real samples/mM } \\
\cline { 2 - 3 } & Stripping voltammetry & Spectrophotometry \\
\hline \multirow{2}{*}{$1 \#$} & 0.0531 & 0.0522 \\
$2 \#$ & 0.0133 & 0.0141 \\
$3 \#$ & 0.021 & 0.022 \\
$4 \#$ & 0.989 & 1.012 \\
\hline
\end{tabular}

Samples 1\# to $4 \#$ are electronic material scraps from different electronics products.

current, the concentration of $\mathrm{Cr}(\mathrm{VI})$ in a real sample solution could be easily and accurately calculated.

Merits of TOA/CPE in an analytical process: reproducibility and detection limit of the method

Under the optimum experimental conditions, the detection limit was obtained as $3.4 \times 10^{-9} \mathrm{M}(S / N=3)$. The reproducibility in the preparation of different TOA/CPE for determining $\mathrm{Cr}(\mathrm{VI})$ is excellent in terms of the experimental results. The relative standard deviation (RSD, \%) for eight measurements was less than 3\%. Furthermore, TOA/CPE had a stable response to $\mathrm{Cr}(\mathrm{VI})$ for the following six months. The above results prove that TOA/CPE has good reproducibility and stability, and a low detection limit.

\section{Analysis of real sample}

Four kinds of electronic material scraps were pretreated; the obtained determination results from stripping voltammograms are given in Table 2. For a comparison, $\mathrm{Cr}(\mathrm{VI})$ concentrations in electronic material scraps have also been determined by UV-visible spectrophotometry. The determined results of these two methods were close, which means that the accuracy of the electrochemical method was satisfactory. As can be seen, the TOA/CPE could be successfully applied to the determination of trace amounts of $\mathrm{Cr}(\mathrm{VI})$ in electronic material scraps.

\section{Conclusion}

In this work, TOA/CPE was successfully utilized to determine
$\mathrm{Cr}(\mathrm{VI})$ in electronic material scraps. This method can accurately determine $\mathrm{Cr}(\mathrm{VI})$ in the presence of $\mathrm{Cr}(\mathrm{III})$ (600-fold concentration); the detection limit is $3.4 \times 10^{-9} \mathrm{M}$, which proves that this method has both high selectivity and sensitivity. Furthermore, this method is convenient and inexpensive, and the precision, reproducibility and stability of the method were satisfactory.

\section{Acknowledgements}

The authors gratefully acknowledge financial support from the Natural Science Foundation of Jiangsu Province (BK2008543), the Fine Petroleum Chemical Key Laboratories Foundation of Jiangsu Province (KF0701), the Technology Research Foundation of Jiangsu Polytechnic University (ZMF07020026), the Foundation of Jiangsu Education (08KJD150012), and the National Science Foundation of China (2008Z0041).

\section{References}

1. J. W. Sue, C. Y. Tai, W. L. Cheng, and J. M. Zen, Electrochem. Commun., 2008, 10, 277.

2. B. K. Jena and C. R. Raj, Talanta, 2008, 76, 161.

3. E. Pehlivan and S. Cetin, J. Hazard. Mater., 2009, 163, 448 .

4. D. Verma, S. K. Verma, and M. K. Deb, Talanta, 2009, 78, 270.

5. D. M. Adriá-Cerezo, M. Llobat-Estellés, and A. R. Maurí-Aucejo, Talanta, 2000, 51, 531.

6. P. Liang, T. Shi, H. Lu, Z. Jiang, and B. Hu, Spectrochim. Acta, Part B, 2003, 58, 1709.

7. J. Yoon, E. Shim, S. Bae, and H. Joo, J. Hazard. Mater., 2009, 161, 1069

8. I. Heidmann and W. Calmano, Sep. Purif. Technol., 2008, $61,15$.

9. N. A. Carrington, L. Yong, and Z. Xue, Anal. Chim. Acta, 2006, $572,17$.

10. O. Domínguez-Renedo, L. Ruiz-Espelt, N. GarcíaAstorgano, and M. J. Arcos-Martínez, Talanta, 2008, 76, 854.

11. A. Safavi, N. Maleki, and H. R. Shahbaazi, Talanta, 2006 68,1113

12. Y. Tian and F. Yang, J. Clean. Prod., 2007, 15, 1415.

13. R. A. Kumbasar, Sep. Purif. Technol., 2008, 64, 56.

14. Z. D. Chen, W. L. Tong, W. C. Wang, Y. Kong, and N. Mitsuzaki, Electron. Compon. Mater., 2008, 27, 26.

15. M. W. Ashraf and A. Mian, Environ. Toxicol. Chem., 2006, 88, 187.

16. Y. Shi, H. Sun, D. Lu, Q. Le, D. Chen, and Y. Zhou, Sep. Purif. Technol., 2006, 49, 20.

17. S. W. Jiang, X. Y. Miao, and T. G. Wang, Tianjin Chem. Indus., 2007, 21, 51

18. J. Li, S. Gao, H. Duan, and L. Liu, Waste Manage., 2009 , in press.

19. T. Ólmez, J. Hazard. Mater., 2009, 162, 1371.

20. H. L. Zhang, Y. K. Ye, and B. Xu, Chin. J. Anal. Chem., 2000, 28, 194

21. K. L. Šebojka and L. Milivoj, Electroanalysis, 1996, 8, 959.

22. I. Turyan and D. Mandler, Anal. Chem., 1997, 69, 894 